Queen's Hall on Sept. 21, conversaziones at the Royal Institution and the Institution of Electrical Engineers on Sept. 22, and the opening of the Faraday Exhibition at the Albert Hall to the public on Sept. 23. This exhibition will remain open for about ten days, and it is hoped to publish a catalogue and description of it. The preparation of a souvenir of the whole celebrations is under consideration, and progress is being made with the preparation for publication of Faraday's famous diary. Of the six or eight volumes in which the work will ultimately be completed, it is hoped to have one or possibly two ready by September.

The second day of the Faraday celebrations, Sept. 22, will coincide with the opening of the summer meeting of the Institution of Electrical Engineers; while the third day, Sept. 23, will be the commencement of the centenary meeting of the British Association for the Advancement of Science, which has not hitherto met in London. During the afternoon of Sept. 23, Lieut. Gen. the Right Hon. J. C. Smuts will be installed as president of the British Association and a reception of delegates will be held in the Albert Hall, this arrangement allowing the members to have a private view of the Faraday Exhibition. On the same evening General Smuts will deliver his address at the inaugural general meeting in the Central Hall, Westminster. The sectional and other scientific transactions will be carried on daily from Thursday, Sept. 24, until Wednesday, Sept. 30, inclusive. For the majority of these transactions meeting-rooms will be used in and near Exhibition Road, South Kensington, while the reception room will be in the Great Hall of the University of London. A preliminary notice has been issued by the Association giving the names of the presidents of the thirteen sections, among whom are Sir J. J. Thomson, Sir Alfred Ewing, Sir Halford Mackinder, Sir Harold Hartley, Sir C. Grant Robertson, and Sir John Russell. The usual programme of visits and excursions will be arranged, and in view of the very large number of institutions and buildings, houses, and memorials in London connected with the scientific men of the past, and the wealth of scientific work now being done in the metropolis, these should prove of wide and general interest. A large attendance of scientific workers from both the Dominions and foreign countries is expected, for whom the Association hopes to obtain private hospitality by residents in London. The full preliminary programme is expected to be issued in April, and this will be obtainable from the Secretary, British Association, Burlington House, W.1.

In addition to these congresses, two other scientific gatherings of unusual interest will be held in Great Britain. At Manchester on Mar. 17 the Manchester Literary and Philosophical Society will commemorate the 150th year of its foundation, while at Cambridge on Oct. 1-2 the centenary of the birth of James Clerk Maxwell will be celebrated. Founded in February 1781, the Manchester Literary and Philosophical Society will always be associated with the work of Dalton, who for half a century was a member. Other distinguished scientific men connected with the Society include Joule, Sturgeon, Hodgkinson, Fairbairn, Nasmyth, Wilde, Osborne Reynolds, Balfour Stewart, and Roscoe. The commemoration will include an address in the Athenæum Hall by Sir J. J. Thomson, to whom the Dalton Medal will be presented, and a dinner in the Midland Hotel. During the week the Society's house, 36 George Street, will be open to visitors. At the Maxwell centenary celebrations at Cambridge, addresses will be given by Sir James Jeans, Sir Joseph Larmor, Sir J. J. Thomson, and Profs. Einstein, Langevin and Planck. Maxwell was born on June 13,1831 , and died on Nov. 5, 1879. He was the first Cavendish professor of experimental physics and the founder of the great school of experimental physics at Cambridge. His contributions to optics, geometry, molecular physics, and other subjects are to-day less widely known than his fundamental work on electromagnetic theory, and his connexion with Faraday makes it appropriate that his centenary should follow the September celebration of the centenary of Faraday's discovery of electromagnetic induction.

\title{
Glasses for Use with Invisible Rays.*
}

By Dr. S. English, Holophane Research Laboratory.

WHENEVER light is produced, invisible radiations-ultra-violet (U.V.) or infra-red (I.R.) - are, almost without exception, produced at the same time. Glasses which are transparent to the visible rays are not necessarily transparent to either the ultra-violet or infra-red; and similarly, opacity to one set of radiations does not imply opacity to the other two sets. In order to control these invisible rays, therefore, it is necessary to have ranges of glasses for transmitting and for absorbing these various bands of rays.

\section{Ultra-VIOLET RAdiation.}

Of recent years the extraordinary biological activity of a small band of ultra-violet rays lying

Substance of a paper read before the Illuminating Engineering Soclety on Dec. 12.

$$
\text { No. 3200, VoL. 127] }
$$

near the extreme end of the sun's spectrum, and extending from this wave-length $(295 \mathrm{M} \mu)$ up to about $320 \mathrm{M} \mu$, has established the fact that though ordinary glass, as used for windows and artificial lighting equipment, is transparent to the longest ultra-violet rays, it becomes opaque at about 310$320 \mathrm{M} \mu$. It is thus useless for transmitting rays of the biologically active wave-lengths. Several types of glass have been developed which are transparent to these so-called 'health rays', and to a limited extent to radiations of rather shorter wavelengths than are found in the sun's spectrum.

Investigations in this field have proved that silica and boric oxide are the best two materials for making glass with a good transparency for the ultra-violet, while iron oxide and titania are the two most dangerous oxides in this respect. In 
making U.V. glass, besides reducing the amount of iron oxide entering the glass from various sources, it has been found necessary to melt the glass under chemically reducing conditions, for ferric oxide reduces the U.V. transparency much more than does a corresponding amount of ferrous oxide. For this purpose organic reducing agents are generally used, but recently, in some cases, inorganic reducing agents have been used very successfully. With these inorganic reducing agents it is possible to obtain a higher proportion of the total iron oxide content of a glass in the ferrous condition, and as a result the colour of the glass through a considerable thickness is pale blue, whereas the colour of glass reduced with organic agents is pale green or bluegreen, or it may be a pale amber colour if too much carbonaceous matter has been used.

In connexion with that much-debated matter, the ageing of U.V. glasses, it has been shown that certain types of glass more easily lose a certain proportion of their transparency to the ultra-violet than do others. This loss of U.V. transparency appears to be due to the reoxidation of the ferrous iron in the glass to the ferric state, a process which proceeds slowly under the influence of direct sunlight until an equilibrium between the relative amounts of the two oxides is reached. When once this equilibrium is reached, no further loss of U.V. transparency occurs unless the conditions of exposure are altered. The extent of this loss of U.V. transparency depends on the total iron oxide content of the glass and on the conditions of manufacture ; it varies from so low a figure as 7 per cent at $300 \mathrm{M} \mu$ for one type of glass up to 20 per cent or more for other types.

For the manufacture of medical and scientific U.V. lamps, clear fused quartz is an ideal material, but it is too transparent to the shorter ultra-violet rays and too expensive when worked into the desired sizes and shapes that are required for certain new types of U.V. lamps. These lamps, it is claimed, give sufficient ultra-violet light of the

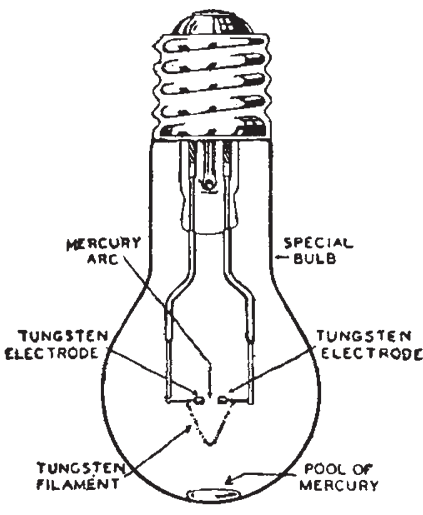

FIG. 1.-New type of U.V. lamp. active wave-lengths to produce a light erythema; but, it is also claimed, they are safe to use - continuously without medical supervision - either as a substitute for, or in parallel with, ordinary artificial lighting. One of these lamps consists of a daylight blue globe of U.V. transparent glass surrounding a tungsten filament, which is distinctly over-run, so much so that its average life is reduced to 300 hours. Another lamp has a clear U.V. glass bulb containing a drop of mercury, a tungsten filament, and tungsten electrodes between which a mercury vapour arc is struck almost as soon as the lamp is switched on, the heat from the filament being sufficient to vaporise enough mercury to start and maintain the arc (Fig. 1). A third lamp of this type is a low-pressure mercury arc enclosed within a vitreosil tube which is surrounded by a framework carrying sheets of U.V. glass. The

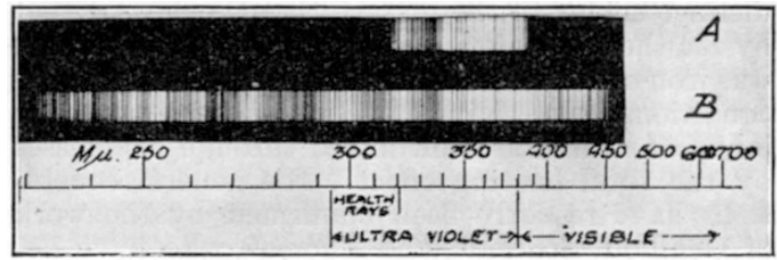

FIG. 2.-A, iron arc through Wood's glass ; B, iron arc.

lamp is meant for use along with ordinary artificial lighting units.

Glasses containing sufficient nickel oxide on a potash base to colour them a very deep blue are so deep that in thicknesses of $\mathbf{3} \mathrm{mm}$. they are opaque to ordinary light, but are transparent to ultra-violet rays from about $390 \mathrm{M} \mu$ down to about $310 \mathrm{M} \mu$ (Fig. 2). They are referred to as Wood's glasses. With such glass it is possible to have a room completely dark but flooded with ultra-violet rays that only need to impinge on suitable fluorescent materials to reveal their presence. One such material is the so-called canary glass, which owes its fluorescent properties to the presence of a small percentage of uranium oxide on a soda lime base. Under the action of ultraviolet rays, this glass shows a very strong greenishyellow fluorescence. Certain other glasses show a weak fluorescence, but none of them is in any way comparable to uranium glass in this respect. Besides its attempted use in invisible signalling, Wood's glass is finding many avenues of usefulness in research and commercial laboratories.

For absorbing ultra-violet rays while at the same time transmitting the visible spectrum without very much selective absorption, there are several glasses available, all based on Sir William Crookes's work, and all containing, as an essential constituent, cerium oxide. If selective absorption in the visible region is not objected to, then an amber-coloured glass made by the inclusion of iron oxide and manganese dioxide in the batch is very effective in absorbing ultra-violet rays.

\section{INFRA-RED Radiation.}

On turning to the infra-red rays, extending from $0.78 \mu$ upwards, we again have three types of glass : (1) for transmitting both visible and infra-red rays ; (2) for transmitting the visible and absorbing the infra-red; and (3) for absorbing the visible and transmitting the infra-red. Considering them in this order, fused quartz, which of course transmits the vision rays freely, also transmits the infra-red radiations up to a wave-length of about $5 \mu$. It is not to be expected that glasses containing 70-75 per cent of silica will show any better infra-red transparency. Soda and lime, the other principal constituents of ordinary glass, appear to cause a

$$
\text { No. 3200, VoL. 127] }
$$


slightly decreased infra-red transparency, but this may be due to small amounts of impurities that are usually found in such glasses.

Sir William Crookes, in his work published in 1914, showed that many oxides conferred on glass the property of absorbing the infra-red rays to varying extents. Most of these oxides also gave a distinct colour to the glass. He also showed that by far the most effective material for this purpose was iron oxide melted into the glass under reducing conditions. In his work Crookes measured the infra-red radiation transmitted through his glasses by the total heating effect. His general conclusions have recently been confirmed by the work of Gehlhoff, Schmidt, and Thomas, who have determined the infra-red transmissions at various wave-lengths.

Several heat-absorbing glasses are available. They all employ iron oxide in the reduced condition, the only essential difference being the means that are employed to obtain the iron oxide in the ferrous state. Generally the iron and its reducing agent are introduced together by using iron oxalate as Crookes did. Recently, however, attempts have been made, with a certain degree of success, to use inorganic reducing agents, which retain a greater proportion of the iron in the ferrous state. Such glasses are blue-green in colour, instead of the green of ordinary iron-containing glasses.

Measurements show that the heat absorption of glasses of this type is to a certain extent related to the colour of the glass, but there is no close parallel, as is shown in the accompanying table.

Light Trangmission and Heat Absorption of Various Glasses, 2.5-3.0 Mm. Thick.

\begin{tabular}{|c|c|c|c|c|c|}
\hline \multirow{2}{*}{\multicolumn{2}{|c|}{ Glass. }} & \multirow{2}{*}{$\begin{array}{c}\text { Percentage } \\
\text { heat } \\
\text { absorption. }\end{array}$} & \multicolumn{3}{|c|}{$\begin{array}{l}\text { Percentage light trans- } \\
\text { mission. }\end{array}$} \\
\hline & & & Red. & Green. & Blue. \\
\hline H. (Clear) & & 74 & 59 & 72 & 71 \\
\hline T. (Clesx) & & 72 & 59 & 71 & 71 \\
\hline C. (Cath.) & & 93 & 17 & 36 & 35 \\
\hline A. (Clear) & . & 79 & 59 & 75 & 75 \\
\hline 5. (Experi & iental) & 86 & 50 & 70 & 69 \\
\hline 12. (Experi & Lental) & 93 & 25 & 45 & 44 \\
\hline
\end{tabular}

As a last type of glass to be considered, there is a very interesting glass which has the power of absorbing all visible rays but transmitting infra-red rays. Such a glass, of course, appears black in thickness of $2 \mathrm{~mm}$. and upwards, but in very thin sections it has a reddish amber colour. As a means of invisible signalling, this glass has almost, if not quite, superseded Wood's glass, since infra-red rays are easier to produce in quantity than ultra-violet rays ; they also have the great advantage of carrying farther, as they are not so easily absorbed by the atmosphere. For burglar alarms and apparatus of that type, this glass has an interesting field of usefulness.

\section{British Industries Fair.}

$\mathrm{T}$ HE British Industries Fair, 1931, to which brief reference was made in our last issue (p. 281), has exceeded its previous records in the total area occupied by the stands, in the number of exhibitors, and probably, also, so far as the evidence is available at the time of writing, in the number of overseas and home buyers, as well as of the general public, that have visited it. The integrated effort to demonstrate visually the extent, variety, and quality of the products of British industry required this year no less than four separated, but not unrelated, exhibitions: for the light industries, at Olympia, London; for the heavy industries, at Birmingham ; for textiles, at the White City, London ; and for artificial silk goods, at the Albert Hall, London. In the critical industrial period through which the country is now passing, the Fair was a remarkable and bold achievement, and tribute must be paid to the Department of Overseas Trade, to the Birmingham Chamber of Commerce, and to the various trade and industrial organisations, as well as to individual firms, that co-operated in its organisation. Information is not yet available, but will be eagerly awaited, as to the business orders that have been received for British goods, as the direct result of the Fair.

It will not be possible to review, even cursorily, the exhibits shown at the four separate sections of the Fair mentioned above, but it may be worth while to record a general impression of the exhibi- tions at Olympia. It is difficult to believe that any visitor could thoughtfully go through the Fair without being greatly impressed by the vast range, the great variety, the excellent quality, and often, be it said, the great beauty of the goods displayed. Despite the disheartening aspect of our unemployment figures and the faintness of our hopes of an early industrial revival, the evidence that Olympia afforded of the vigour and quality of so many British industries was reassuring and uplifting. An industrialist, recently returned from journeying overseas, related that, in foreign countries and in the British dominions overseas, he had again and again noted how confident was the expectation that, whatever might happen in other countries, Great Britain at least would win through the difficulties of the world slump. What could be seen at Olympia went far to justify this confidence. In the heavy industries and in the great staple exporting industries, Great Britain has been for so long in the forefront that the quality of their products has almost come to be taken for granted; but even in those lighter industries associated in the popular mind with foreign manufacture-for example, toys and certain kinds of fancy goodsthe exhibits at Olympia provided striking evidence of the progress that has been made by British manufacturers.

The grouping of the exhibits according to industries was not only convenient for the buyer and

No. 3200, VoL. 127] 